\title{
1 The genetics of gene expression in a C. elegans multi parental recombinant
}

\section{2 inbred line population.}

3 Basten L. Snoek ${ }^{1,2,+}$, Mark G. Sterken ${ }^{1}$, Harm Nijveen ${ }^{3}$, Rita J.M. Volkers ${ }^{1}$, Joost Riksen ${ }^{1}$, Philip C.

4 Rosenstiel ${ }^{4,5}$, Hinrich Schulenburg ${ }^{6,7,+}$, Jan E. Kammenga ${ }^{1,+}$.

$5 \quad{ }^{1}$ Laboratory of Nematology, Wageningen University, Droevendaalsesteeg 1, NL-6708 PB Wageningen, The Netherlands

$6{ }^{2}$ Theoretical Biology and Bioinformatics, Utrecht University, Padualaan 8, $3584 \mathrm{CH}$ Utrecht, The Netherlands

$7 \quad{ }^{3}$ Bioinformatics Group, Wageningen University, Droevendaalsesteeg 1, NL-6708 PB Wageningen, The Netherlands

$8{ }^{4}$ Institute for Clinical Molecular Biology, University of Kiel, 24098 Kiel, Germany

$9{ }^{5}$ Competence Centre for Genomic Analysis (CCGA) Kiel, University of Kiel, 24098 Kiel, Germany

$10 \quad{ }^{6}$ Zoological Institute, University of Kiel, 24098 Kiel, Germany

$11{ }^{7}$ Max Planck Institute for Evolutionary Biology, August-Thienemann-Str. 2, 24306 Ploen, Germany

$12+$ Corresponding authors

Keywords: Multi parental RILs, expression QTL, eQTL, SNPs, C. elegans

15

1.b.snoek@uu.nl; 0000-0001-5321-2996

harm.nijveen@wur.nl; 0000-0002-9167-4945

19 rvolkers@hotmail.com;

20 joost.riksen@wur.nl;

21 p.rosenstiel@mucosa.de;

22 hschulenburg@zoologie.uni-kiel.de; 0000-0002-1413-913X

23 jan.kammenga@wur.nl; 0000-0003-4822-4436 


\section{Abstract}

26 Studying genetic variation of gene expression provides a powerful way to unravel the molecular components

27 underlying complex traits. Expression QTL studies have been performed in several different model species,

28 yet most of these linkage studies have been based on genetic segregation of two parental alleles. Recently

29 we developed a multi-parental segregating population of 200 recombinant inbred lines (mpRILs) derived

30 from four wild isolates (JU1511, JU1926, JU1931 and JU1941) in the nematode Caenorhabditis elegans.

31 We used RNA-seq to investigate how multiple alleles affect gene expression in these mpRILs. We found

321,789 genes differentially expressed between the parental lines. Transgression, expression beyond any of

33 the parental lines in the mpRILs, was found for 7,896 genes. For expression QTL mapping almost 9,000

34 SNPs were available. By combining these SNPs and the RNA-seq profiles of the mpRILs, we detected

35 almost 6,800 eQTLs. Most trans-eQTLs (63\%) co-locate in six newly identified trans-bands. The trans-

36 eQTLs found in previous 2-parental allele eQTL experiments and this study showed some overlap (17.5\%-

$3746.8 \%$ ), highlighting on the one hand that a large group of genes is affected by polymorphic regulators

38 across populations and conditions, on the other hand it shows that the mpRIL population allows

39 identification of novel gene expression regulatory loci. Taken together, the analysis of our mpRIL

40 population provides a more refined insight into $C$. elegans complex trait genetics and eQTLs in general, as

41 well as a starting point to further test and develop advanced statistical models for detection of multi-allelic

42 eQTLs and systems genetics studying the genotype-phenotype relationship. 


\section{Introduction}

44 Investigation of the genotype-phenotype relationship is at the heart of genetic research. The detection and

45 description of allelic variants and genetic mechanisms have been a demanding task due to the quantitative nature of most phenotypic variation. Quantitative trait locus (QTL) mapping has been one of the methods

47 of choice for finding the loci on which these allelic variants can be found. Many functional polymorphisms

48 in plants and animals, including many model species such as model nematode C. elegans, have been

49 discovered using QTL mapping [1-25]. Over the last decade molecular phenotypes such as transcript levels,

50 protein levels and metabolites have also been used in QTL mapping [26-32]. Heritable variation in these

51 molecular phenotypes often plays a role in heritable phenotypic variation [10, 30, 33]. Mapping expression

52 QTLs (eQTLs) can provide insight into the transcriptional architecture of complex traits and have been

53 conducted in model species such as Arabidopsis thaliana and C. elegans as well as several other taxa [26,

$54 \quad 28-31,34-41]$.

Most eQTL studies have been done on populations of recombinant inbred lines (RILs) originating

from a cross between two different parental genotypes [26, 28-31, 34-40]. Inclusion of more than two parents can capture more genetic variation, increasing the number of detected QTLs, potentially allowing more precise mapping and therefore reducing the number of potential candidate causal genes to be verified [42]. Such a strategy was first used for Arabidopsis by developing a Multiparent Advanced Generation InterCross (MAGIC) lines population consisting of 527 RILs developed from 19 different parental accessions [43]. Several other MAGIC populations have been developed since then for a range of species, including $C$. elegans [44-46].

Recently multi parental RIL (mpRILs) populations have been developed in C. elegans [45, 46].

64 These populations have been created using other strains than the most frequently used N2 strain and the

65 Hawaiian CB4856 strain [26-31, 37, 47-61]. In this study we used the population of $200 \mathrm{mpRILs,} \mathrm{derived}$ 
69 between the four parental genotypes and used to identify QTLs for life-history traits [45]. The RNA was

70 sampled from the mpRILs grown under standardised conditions $\left(24^{\circ} \mathrm{C}, \mathrm{OP} 50,48 \mathrm{~h}\right.$ after bleaching $)$ and

71 obtained from animals from two 6-cm dishes, with one RNA-seq replicate per mpRIL and two per parental

72 isolate. To investigate the effect of multiple genetic backgrounds on gene expression, we used the RNA-

73 seq data to associate gene expression levels to genetic variants present in the population. We compared the

74 gene expression level differences between the parental wild isolates, calculated transgression, as well as

75 heritability and mapped eQTLs. We identified six trans-bands, hotspots at which many trans-eQTLs co-

76 locate, which we further studied by gene ontology enrichment. Lastly, we compared the eQTLs found in

77 this study to the eQTLs found in previous eQTL studies in C. elegans [26, 28, 30, 31, 37, 39]. Together

78 these results present the first insights into the genetic architecture of gene expression in a C. elegans multi

79 parental RIL population. 
bioRxiv preprint doi: https://doi.org/10.1101/2021.03.04.433879; this version posted March 4, 2021. The copyright holder for this preprint (which was not certified by peer review) is the author/funder, who has granted bioRxiv a license to display the preprint in perpetuity. It is made available under aCC-BY-NC 4.0 International license.

80

81

82

83

84

85

86

87

\section{Results}

\section{Gene expression differences between the parental lines}

To study the effect of genetic variation on gene expression we used RNA-seq on a population of 200 multi parental recombinant inbred lines (mpRILs) [45], made from a cross between four parental lines isolated from Orsay, France (JU1511, JU1941) and Santeuil, France (JU1926, JU1931) [62]. The animals used were grown on two 6-cm dishes $\left(24^{\circ} \mathrm{C}\right.$, OP50, $48 \mathrm{~h}$ after bleaching) per sample pooled for RNA isolation, with one RNA-seq replicate per mpRIL and two per parental isolate. First, we determined the expression differences between the parental lines (Supplement table 1). Of the 12,029 detected transcripts we found 1,789 genes differently expressed between at least one parental pair (TukeyHSD $\mathrm{p}<0.001$; FDR $<0.05$;

Figure 1). Of the four strains, JU1926 was most different when compared to the other lines, with 409 genes being differently expressed between JU1926 and the other three lines. Thereafter, JU1941 was most different from the remaining two lines. These differences in gene expression between the parental lines are likely genotype dependent.

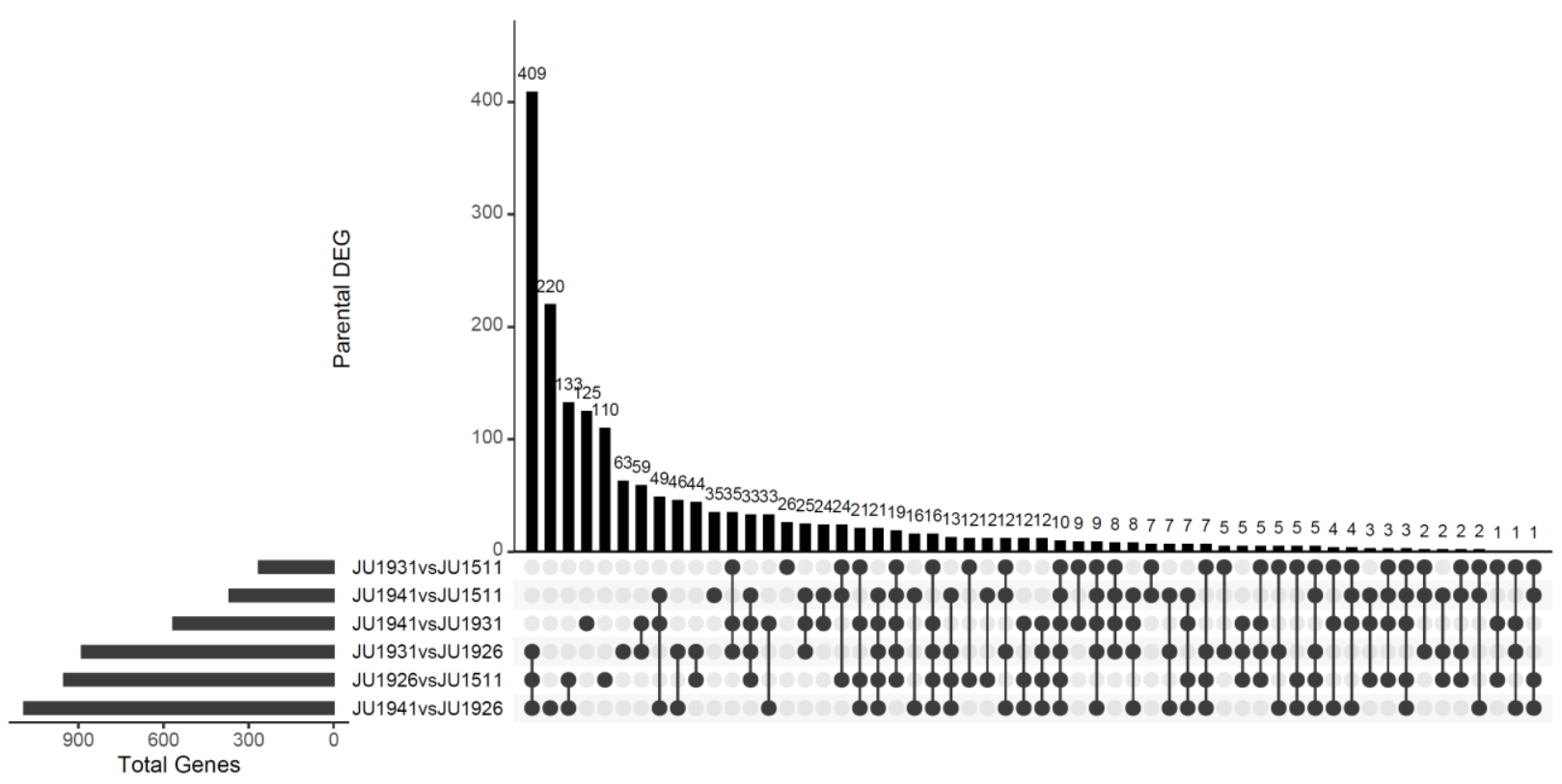

Figure 1: Gene expression differences between the four mpRIL parental lines. Upset plot shows the pairwise comparisons and the overlap between the pairs (TukeyHSD; $<<0.001$; FDR=0.05). The horizontal bar plot shows the number of differentially expressed genes per parental pair, while the vertical bar plot indicates the number of shared differentially expressed genes per comparison. For example, an overlap of 409 genes was found between the three comparisons that include the JU1926 parental line, 


\section{Transgression and Heritability}

101

To explore the variation in gene expression between the different parental and mpRIL genotypes we applied principal component analysis on the $\log _{2}$ gene expression ratios (Figure2A). Here we can see that the expression variation in many of the mpRILs extends beyond the parental expression variation, which suggests transgression. We quantified this and found transgression for 7,896 genes (FDR $=0.08$; Figure2Bcomplex genetic interactions such as epistasis.

A

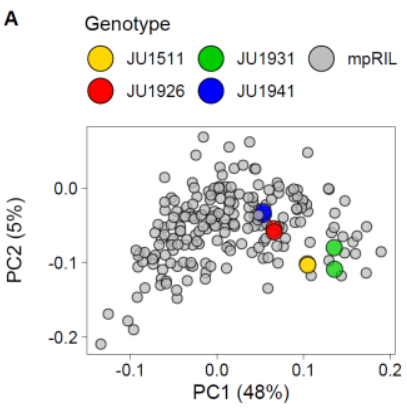

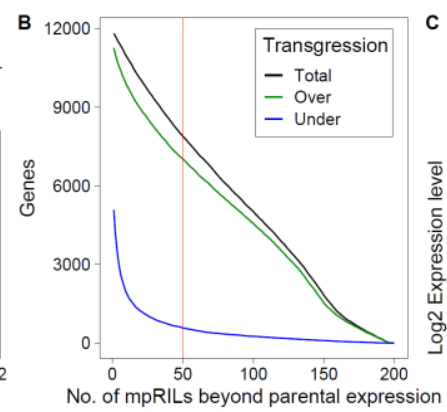
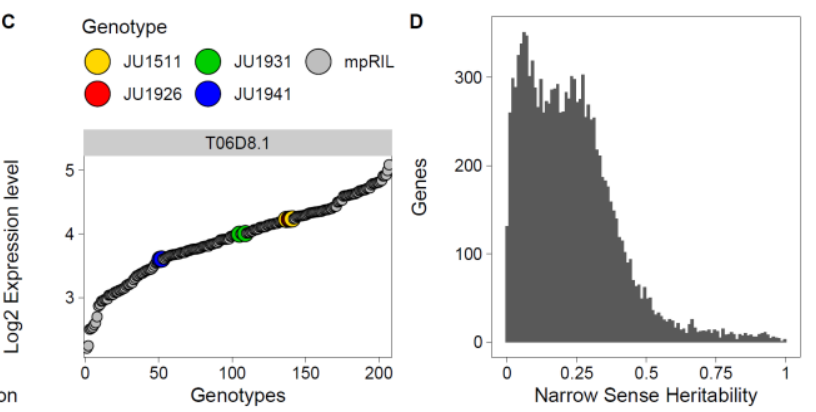

Figure 2: Gene expression variation in the mpRILs and parental genotypes. A) Principal component analysis (PCoA) of the $\log _{2}$ ratios, mpRILs shown in grey, parental lines shown in colour. B) Transgression: number of mpRILs beyond the parental expression level (x-axis) against the number of genes (y-axis). The mpRILs below (under) the lowest parental expression level in blue, mpRILs over the highest parental expression level in green and the sum of these (total) in black. C) Example of two-sided transgression for expression levels of gene T06D8.1. D) Genes with significant narrow sense heritability $\left(h^{2}\right)$ and the distribution of heritable variation of gene expression variation at $\mathrm{FDR}=0.05$.

To find the loci involved in gene expression variation between the mpRILs we used a single marker QTL 
125 chromosome V and most trans-eQTLs on chromosomes I and X. For both cis- and trans-eQTLs, fewest

126 where found on chromosome II and IV. The SNP Distribution Pattern (SDP) groups SNPs with the same

127 distribution in the parental lines. When the SDP is considered, many of the cis-eQTLs were found to have

128 an effect where either the JU1511 or JU1941 allele was different from the three other parental genotypes.

129 For the trans-eQTLs the largest groups also show this allelic difference or those SNPs that distinguish

130 JU1511/JU1941 from JU1926/JU1931. A substantial group was found for the JU1931 allele, whereas hardly

131 any were found for the JU1926 specific SNPs. The lack of JU1926 is somewhat surprising as it had the most

132 differentially expressed genes (DEG) in the comparison of the parental lines, however we found much more

133 genes with eQTLs than being DEG in the parental comparison. These are much more likely to be caused by

134 new allelic combinations present in the mpRILs. Overall, the majority of the eQTLs are found on a few

135 major effect loci with a specific SDP linkage (Figure 3). Moreover, comparing the $h^{2}$ to the eQTLs showed

136 that genes with an eQTL have a much higher $h^{2}$ than those without an eQTL, where genes with an $h^{2}>0.25$

137 almost all have an eQTL (Figure 4). Comparing cis- and trans-eQTLs showed that genes with a cis-eQTL

138 have a higher $h^{2}$ on average, yet the $h^{2}$ distributions of cis- and trans-eQTLs are overlapping.

140 Table 1: eQTLs per type (cis/trans) per chromosome per SNP Distribution Pattern (SDP).

\begin{tabular}{|c|c|c|c|c|c|c|c|c|c|c|c|c|c|c|}
\hline & Cis & & & & & & & Tran & & & & & & \\
\hline SDP & I & II & III & IV & V & $X$ & Tot & I & II & III & IV & V & $\mathbf{X}$ & Tot \\
\hline $\begin{array}{l}12 \\
\text { JU1511 \& JU1926 vs. } \\
\text { JU1931 \& JU1941 }\end{array}$ & 14 & 2 & 17 & 2 & 23 & 13 & 71 & 35 & 0 & 1 & 1 & 3 & 67 & 107 \\
\hline $\begin{array}{l}3 \\
\text { JU1511 \& JU1931 vs. } \\
\text { JU1926 \& JU1941 }\end{array}$ & 6 & 1 & 14 & 39 & 41 & 3 & 104 & 0 & 2 & 106 & 13 & 15 & 27 & 163 \\
\hline $\begin{array}{l}14 \\
\text { JU1511 \& JU1941 vs. } \\
\text { JU1926 \& JU1931 }\end{array}$ & 12 & 0 & 19 & 0 & 53 & 11 & 95 & 1373 & 0 & 119 & 5 & 103 & 44 & 1644 \\
\hline JU1511 & 37 & 32 & 61 & 14 & 18 & 81 & 243 & 457 & 28 & 211 & 20 & 9 & 430 & 1155 \\
\hline JU1926 & 0 & 32 & 4 & 59 & 5 & 1 & 101 & 5 & 44 & 5 & 26 & 10 & 5 & 95 \\
\hline JU1931 & 8 & 0 & 15 & 3 & 81 & 1 & 108 & 31 & 0 & 12 & 21 & 919 & 2 & 985 \\
\hline JU1941 & 76 & 0 & 66 & 5 & 38 & 22 & 207 & 150 & 1 & 155 & 35 & 94 & 1271 & 1706 \\
\hline Total & 153 & 67 & 196 & 122 & 259 & 132 & 929 & 2051 & 75 & 609 & 121 & 1153 & 1846 & 5855 \\
\hline
\end{tabular}


bioRxiv preprint doi: https://doi.org/10.1101/2021.03.04.433879; this version posted March 4, 2021. The copyright holder for this preprint (which was not certified by peer review) is the author/funder, who has granted bioRxiv a license to display the preprint in perpetuity. It is made available under aCC-BY-NC 4.0 International license.

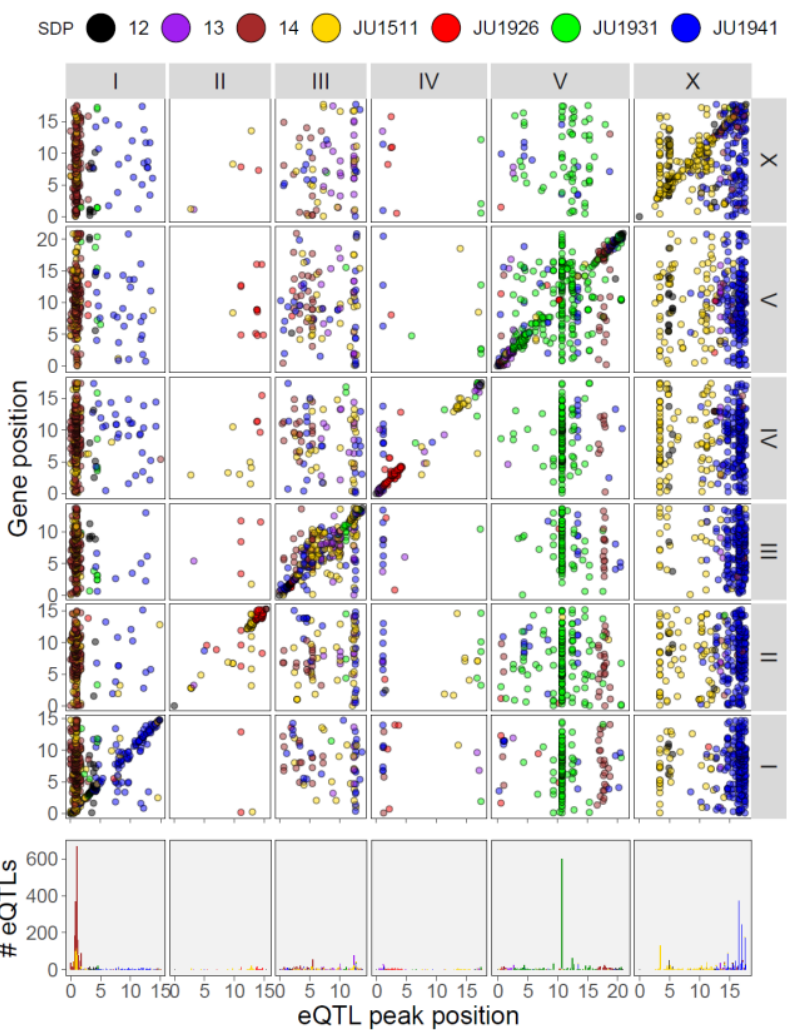

Figure 3: Cis/Trans plot of the identified eQTLs. eQTL position shown on the x-axis, gene position shown on the y-axis (upper plot) or number of eQTLs (bottom plot). SDP shown in colour, chromosomes shown in the grey strips on top and on the right of the panels.
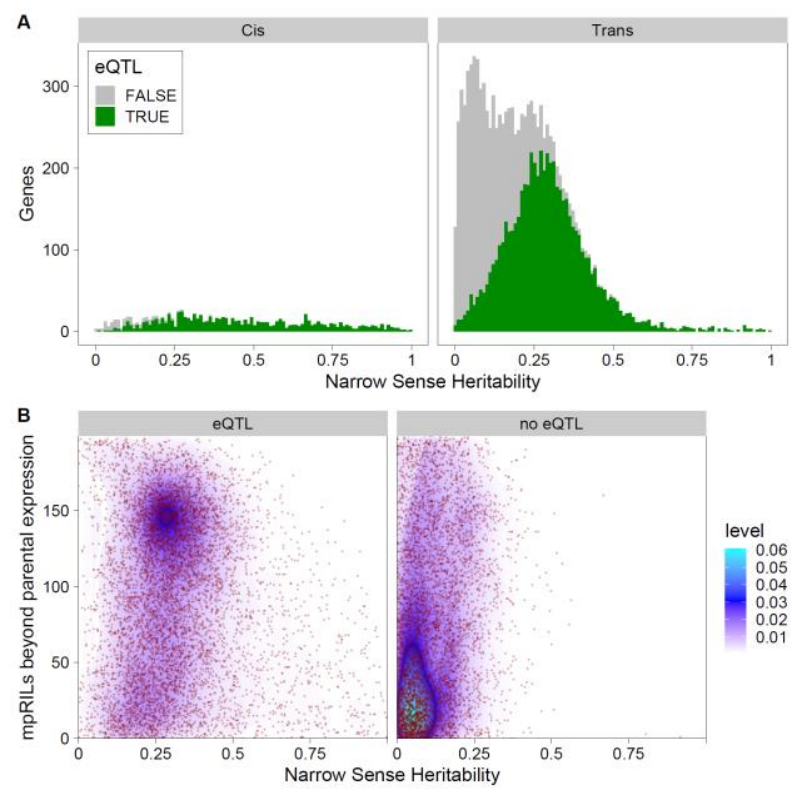

Figure 4: Relation between eQTLs, transgression and Narrow Sense Heritability $\left(h^{2}\right)$. A) Narrow Sense Heritability $\left(h^{2}\right.$; $x-$ axis), distribution in genes (y-axis) with cis- and trans-eQTLs, significance of the eQTLs is TRUE (green) when > 5.35 and FALSE a significant eQTL, individual datapoints shown in red, colour gradient indicates datapoint density. 
bioRxiv preprint doi: https://doi.org/10.1101/2021.03.04.433879; this version posted March 4, 2021. The copyright holder for this preprint (which was not certified by peer review) is the author/funder, who has granted bioRxiv a license to display the preprint in perpetuity. It is made available under aCC-BY-NC 4.0 International license.

\section{Trans-bands}

153 A large majority of the trans-eQTLs $(3,704 ; 63 \%$ of all trans-eQTLs) were found in six hotspots, so called 154 trans-bands (TBs) (number of trans-eQTLs > 100, window 1Mbp to both sides; Table 2; Figure 3). Two 155 TBs were found on chromosome I, one on chromosome V and three on chromosome X. The two TBs on chromosome I co-located but were linked to different SDP: the SDP 14 (JU1511/JU1941 vs

the three TBs found on chromosome X were linked to SPD JU1511 and JU1941.

Table 2: Descriptive overview of the 6 identified trans-bands. SNP Distribution Pattern (SDP), Chromosome, Peak position and

QTLs found in Snoek et al 2019 [45].

\begin{tabular}{|c|c|c|c|c|c|c|c|c|}
\hline & $\underset{\theta}{\mathscr{\theta}}$ & $\underset{7}{2}$ & 胥 & 롤 & 串 & $\sum_{n}^{8}$ & $\begin{array}{l}\text { GO Enrichment } \\
\text { (selection from enrichment table) }\end{array}$ & $\begin{array}{l}\text { Phenotypic } \\
\text { QTL (in } \\
\text { Snoek et al. } \\
\text { 2019 [45]) }\end{array}$ \\
\hline TB1 & $\begin{array}{l}14 \\
\text { (JU1511 \& } \\
\text { JU1941 vs } \\
\text { JU1926 \& } \\
\text { JU1931) }\end{array}$ & $\mathrm{I}$ & 1.03 & 0.03 & 2.03 & 1339 & $\begin{array}{l}\text { thermosensory behaviour, negative regulation of } \\
\text { engulfment of apoptotic cell, DNA replication, } \\
\text { embryonic body morphogenesis, establishment or } \\
\text { maintenance of actin cytoskeleton polarity, muscle } \\
\text { fiber development, epidermis development, } \\
\text { response to unfolded protein and, molting cycle, } \\
\text { collagen and cuticulin-based cuticle, }\end{array}$ & $\begin{array}{l}\text { Population } \\
\text { growth on } \\
\text { Erwinia and on } \\
\text { B. thuringiensis }\end{array}$ \\
\hline TB2 & JU1511 & I & 0.83 & 0 & 1.83 & 443 & $\begin{array}{l}\text { regulation of protein stability, regulation of vulval } \\
\text { development, DNA replication, anaphase-promoting } \\
\text { complex and, microtubule polymerization }\end{array}$ & NA \\
\hline TB3 & JU1931 & $\mathrm{V}$ & 10.74 & 9.74 & 11.74 & 607 & $\begin{array}{l}\text { hemidesmosome assembly, external side of plasma } \\
\text { membrane and, negative regulation of response to } \\
\text { oxidative stress }\end{array}$ & NA \\
\hline TB4 & JU1511 & $\mathrm{X}$ & 3.40 & 2.40 & 4.40 & 133 & few & $\begin{array}{l}\text { heat-shock } \\
\text { sensitivity }\end{array}$ \\
\hline TB5 & JU1941 & $\mathrm{X}$ & 14.69 & 13.69 & 15.64 & 225 & few & $\begin{array}{l}\text { population } \\
\text { growth on } B . \\
\text { thuringiensis }\end{array}$ \\
\hline TB6 & JU1941 & $\mathrm{X}$ & 16.60 & 15.65 & 17.6 & 957 & $\begin{array}{l}\text { embryonic body morphogenesis, DNA replication, } \\
\text { integral component of peroxisomal membrane, } \\
\text { anaphase-promoting complex, endosome, } \\
\text { phagocytic vesicle membrane, neuronal signal } \\
\text { transduction, response to anoxia, cuticle pattern } \\
\text { formation, cell fate commitment, hemidesmosome } \\
\text { associated protein complex and, response to lipid }\end{array}$ & $\begin{array}{l}\text { sensitivity to } \\
\text { oxidative stress }\end{array}$ \\
\hline
\end{tabular}


To study the effect of TBs on biological function we used GO term enrichment (Table 2, Supplement table

3). Each of the TBs was linked to mostly different sets of GO terms, suggesting an effect on different parts

$\mathrm{V}$ were enriched for GO terms associated with oxidative stress. The genes mapping to TB4 and TB5 on

chromosome $\mathrm{X}$ only showed a few GO terms to be enriched and the genes mapping to TB6 on chromosome

$\mathrm{X}$ were enriched for the GO term "response to anoxia" and many more. This shows that these TBs can be involved in several developmental processes and in the interaction with the environment.

180 To investigate if the genes with eQTLs found in the present mpRIL study also had eQTLs in other studies, we compared them with the studies found in WormQTL2 (Table 3; [26, 28, 30, 31, 37, 39, 56]). In general, we found that a substantial group of genes with a trans eQTL in any of the studies had an eQTL in our mpRIL experiment $(26.5 \%-36.9 \%)$. The groups of genes with trans-eQTLs show much higher overlap than the genes with a cis-eQTL in any of the experiments $(10.2 \%-20.0 \%)$. Around a third of the genes with 
to be affected by genetic variation independent of environment or developmental stage, while the loci involved are most likely different in each experiment/condition [28, 30, 31].

Table 3: Overlapping eQTLs between this mpRIL experiment and the RIL experiments available in WormQTL2 [63]. Percentages

\section{eQTL experiment}

Li et al. $200616^{\circ} \mathrm{C}[37]$

Li et al. $200624^{\circ} \mathrm{C}$ [37]

Li et al. 2010 [26]

Rockman et al. 2010 [39]

Snoek \& Sterken et al. 2017 control [28]

Snoek \& Sterken et al. 2017 heat-shock [28]

Snoek \& Sterken et al. 2017 recovery [28]

Sterken et al. 2017 [30]

Vinuela \& Snoek et al. 2010 juvenile [31]

Vinuela \& Snoek et al. 2010 old [31]

Vinuela \& Snoek et al. 2010 reproductive [31] $\begin{array}{ll}\text { Total } & \text { Cis } \\ \text { Cis } & \text { Ove }\end{array}$

240

337

752

1958

961

976

992

719

303

220

348
Cis
Overlap $(\%)$

14.6

12.2998

$14.5 \quad 3544$

$12.0 \quad 2792$

$17.1 \quad 1481$

$20.0 \quad 2776$

$16.1 \quad 1519$

$10.2 \quad 1116$

$11.9 \quad 2206$

$15.0 \quad 1790$

$13.2 \quad 2010$
Trans Overlap (\%)

31.6

30.5

28.7

28.8

36.1

36.9

33.4

26.5

33.4

34.9

32.7

Discussion

204 In this experiment we used a population of multi-parental RILs (mpRILs) and RNA-seq to find 6,784 205 expression quantitative trait loci (eQTLs), of which 929 were cis-eQTLs and 5,855 were trans-eQTLs. A 206 large proportion (63\%) of the trans-eQTLs were found in six trans-bands. The total number of eQTLs found 207 in this mpRIL study $(6,784)$ is at the high end of what was previously found in other experiments (mean: $2,560 ; 653-6,518)[28,30,31,37,39]$. This number is hard to compare as the number of identified eQTLs depend on many factors, such as population size, number of recombinations, statistical model, and RNA measurement technology used, which are nearly all different between this and the other eQTL studies in $C$.

211 elegans [28, 30, 31, 37, 39]. Nevertheless, it seems that a combination of RNA-seq and multiple genetic 212 backgrounds increased the number of detected eQTLs. A very clear increase was found for trans-eQTLs 
$213(5,855)$ compared to the numbers found in previous studies, even at a much lower significance threshold.

214 For example, the study of Rockman et al. 2010 used a comparable number of recombinant inbred advanced

215 intercross lines (RIAILs) as the number of mpRILs in this study ( 200), yet found fewer trans-eQTLs,

216 however the different conditions and technologies used prevent any definitive conclusions. With respect to

217 trans-eQTLs we do know that they depend on environmental conditions or a response to changing

218 conditions. It could be that with a background of four parental genotypes the mpRILs perceive the ambient

219 environment in a broader range than the RIAILs with a background of two parental genotypes used by

220 Rockman et al. 2010, and the RILs in the other studies. For example, the mpRILs could have inherited parts

221 of four different sets of environmental preferences as opposed to two in the RIAILs and RILs, potentially

222 extending the accompanying gene expression patterns and eQTLs. Yet, the most likely reason for the

223 increased number of trans-eQTLs is the use of RNA-seq in this study compared to micro-arrays in the other

224 studies. Another reason for finding more trans-eQTLs could be due to the generally genome-wide equal

225 allelic distributions in this population [45]. Namely, a similar trans-band as the chromosome I trans-band

226 at $1 \mathrm{Mb}$ (TB1) related to development has been spotted before, but has been spurious due to the peel-1 zeel-

2271 incompatibility near that location $[16,28,39]$. Another advantage of using RNA-seq is that the genotype

228 and gene-expression levels can be obtained from the same sample, preventing mis-labelling errors and the

need for "reGenotyping" [64]. In summary, as has been shown for yeast [65], the combination of generally

to pick-up trans-eQTLs in C. elegans and in general.

We previously found QTLs for several different phenotypes, such as population growth on different

the previously found phenotypic QTLs (Table 2). Population growth on Erwinia and on B. thuringiensis

DSM was found to co-locate with TB1, which was enriched for GO terms related to muscle, epidermis, and 
239 heat-shock sensitivity was inferred to co-locate with TB4, however no indication for a link with this

240 phenotype was found in the annotation of the genes with an eQTL at this position. The same was observed

241 for TB5 and the overlap with population growth on B. thuringiensis, where GO enrichment also did not

242 provide any leads to a potential mechanistic link. The overlap between the QTL for sensitivity to oxidative

243 stress and TB6 however did show some clues from GO enrichment as genes involved in the peroxisome as

244 well as DNA replication and cuticle formation could be involved in dealing with oxidative stress.

245 We expect to have only found a fraction of the eQTLs, as we only used a simple additive mapping

246 model, a conservative score of one eQTL per gene, and standard lab conditions with only one time point for

247 RNA isolation. Both the number of eQTLs and genes with one or more eQTLs are expected to increase

248 when more complex models are applied to this data and/or different experimental conditions and time points

249 are considered. Moreover, we use a SNP-based method for eQTL mapping, which has a binary option for

250 each marker and therefore does not consider the genetic origin (parent) of the SNP. Using the genetic origin

251 of the SNPs could reveal the more complex genetic interactions that could underly the differences in

252 transcript levels between the mpRILs. These complex genetic interactions are suggested to be present in this

253 mpRIL population, by the heritability and transgression found. A model in which each marker has the four

254 parental options might indicate loci with more than two alleles affecting gene expression. Furthermore,

255 some (relatively small) genetic loci might have been missed all together as our investigations are based on

256 the N2 reference genome and wild-isolates can have vastly divergent regions of which sequences reads fail

257 to align to the N2 reference genome with conventional methods [49].

258 This study provides a more detailed insight into the genetic architecture of heritable gene expression

259 variation in a multiparent recombinant inbred population. The use of RNA-seq data in combination with

260 more than two alleles allows for a more precise detection of QTLs and incorporates a wider band of standing

261 genetic variation, resulting in a substantial increase in eQTLs especially trans-eQTLs. Comparison to bi-

262 allelic studies supports the position of eQTLs and may be used to detect a more detailed pattern of associated

263 loci. We expect this study, data, and results to provide new insights into C. elegans genetics and eQTLs in 
bioRxiv preprint doi: https://doi.org/10.1101/2021.03.04.433879; this version posted March 4, 2021. The copyright holder for this preprint (which was not certified by peer review) is the author/funder, who has granted bioRxiv a license to display the preprint in perpetuity. It is made available under aCC-BY-NC 4.0 International license.

264 general as well as to be a starting point to further test and develop advanced statistical models for detection 265 of eQTLs and systems genetics studying the genotype-phenotype relationship. 


\section{Methods}

267 Nematode strains and culturing, RNA-sequencing, Construction of the genetic map

268 The $C$. elegans strains and culturing condition, RNA-sequencing and construction of the genetic map can

269 all be found in Snoek et al. 2019. RILs, Genetic map and eQTL profiles can found on WormQTL2 [66]

270 (http://www.bioinformatics.nl/EleQTL; Snoek \& Sterken et al. 2020 [56])

SNP calling and gene expression levels

273 The paired end reads were mapped against the N2 reference genome (WS220) using Tophat [67], allowing

274 for 4 read mismatches, and a read edit distance of 4. SNPs were called using samtools [66], mpileup with

275 bcftools and vcfutils also described in Snoek et al. 2019 [45]. Expression levels were determined using the 276 tuxedo pipeline [68]. Transcripts were assembled from the mapped reads using cufflinks [68]. Raw RNA-

277 seq data can be found in the Sequence Read Archive (SRA; https://www.ncbi.nlm.nih.gov/sra) with ID

278 PRJNA495983. Normalized read-counts can be found on WormQTL2

279 (http://www.bioinformatics.nl/EleQTL; [56])

Heritability and Transgression

282 Heritability of gene expression levels was calculated using the heritability package in " $R$ ". A narrow-sense 283 heritability was calculated using the function marker_h2 [69]. The required kinship matrix was calculated 284 using the emma.kinship function from the EMMA package [70]. To determine significance, we used a 285 permutation approach where we shuffled the expression levels per transcript. After 100 permutations, the $95^{\text {th }}$ highest value was taken as the 0.05 false-discovery rate $[69,71,72]$. Transgression was determined by

287 counting the number of mpRILs with an expression level beyond the mean $+2 \mathrm{SD}$ of the most extreme 288 parental lines. SD was calculated on the within variation of the parental samples. False discovery rate (FDR) 289 was determined by permutations, randomly assigning the parental labels to gene-expression values. 
290 Transgression was evaluated at an arbitrary 50 mpRILs (25\% of all lines; FDR $=0.08)$ beyond the most

291 extreme parental lines.

292

eQTL mapping and FDR

294 For eQTL mapping we first selected the genes with consistently found transcripts, meaning those expressed

295 in at least 20 samples with a mean $\log _{2}$ expression $(\mathrm{fpkm})>-5$. eQTLs were mapped by a linear model using

296 a single maker model explaining gene expression (as $\log _{2}$ ratio with the mean) by one SNP-marker at the

297 time for the whole genome. False Discovery Rate (FDR) was determined by one round of permutations

298 where for each transcript the counts were randomly distributed over the RILs before eQTL mapping. The -

$299 \log _{10}(\mathrm{p})$ value when number of false positives divided by the number of true positives was $<0.01\left(-\log _{10}(\mathrm{p})\right.$

$300>$ 5.35). Genome wide eQTL significance profiles $(-\log 10(\mathrm{p}))$ can be found on WormQTL2

301 (http://www.bioinformatics.nl/EleQTL; [56])

Enrichment analysis and figures

304 Enrichment of GO terms was done using the hyper-geometric test in "R" [73]. GO term genes associations were download from Wormbase (www.wormbase.org) version WS276. Only genes that passed the filtering step for eQTL mapping where used as background genes. For significant enrichment, a p-value $<1 \mathrm{e}^{-5}$ was figure 1 which was made using the UpSetR library.

311 To compare how many genes with an eQTL overlapped between the different studies [26, 28, 30, 31, 37 ,

31239,56 ] available in WormQTL2 [56], we downloaded the eQTL profiles and markers used per experiment

313 and listed the genes with a cis or a trans eQTL. For eQTL determination, the most significant marker per

314 gene was taken as the peak. A $-\log _{10}(\mathrm{p})>3.5$ was use as threshold for calling the eQTL. An eQTL was

315 determined cis when the peak position was within 1Mbp of the start position of the gene. These lists were 
316 compared with the genes having an eQTL in this study. The percentage overlap was calculated against the

317 original study.

319 Acknowledgements

320 We acknowledge financial support from the Deutsche Forschungsgemeinschaft to HS (grant number SCHU

321 1415/11 and project A1 within the CRC 1182), and to PCR (Competence Centre for Genomic Analysis

322 (CCGA) No. 07495230). JK was funded by NIH grant 1R01AA 026658. Furthermore, financial support

323 from the NWO-ALW (project 855.01.151) to RJMV was given. MGS was supported by NWO domain

324 Applied and Engineering Sciences VENI grant (17282). The funders had no role in study design, data

325 collection and analysis, decision to publish, or preparation of the manuscript.

327 Author contributions

328 LBS, HS and JEK conceived the study, RJMV and JR performed the experiments, PCR coordinated and

329 supervised transcriptome sequencing, LBS, MGS and HN analysed the data, LBS wrote the paper with contributions from all authors. 


\section{References}

1. Noble LM, Chang AS, McNelis D, Kramer M, Yen M, Nicodemus JP, Riccardi DD, Ammerman P, Phillips M, Islam T et al: Natural Variation in plep-1 Causes Male-Male Copulatory Behavior in C. elegans. Curr Biol 2015, 25(20):2730-2737.

2. Andersen EC, Bloom JS, Gerke JP, Kruglyak L: A variant in the neuropeptide receptor $n$ pr-1 is a major determinant of Caenorhabditis elegans growth and physiology. PLoS Genet 2014, 10(2):e1004156.

3. Ghosh R, Andersen EC, Shapiro JA, Gerke JP, Kruglyak L: Natural variation in a chloride channel subunit confers avermectin resistance in C. elegans. Science 2012, 335(6068):574-578.

4. Kammenga JE, Doroszuk A, Riksen JA, Hazendonk E, Spiridon L, Petrescu AJ, Tijsterman M, Plasterk RH, Bakker J: A Caenorhabditis elegans wild type defies the temperature-size rule owing to a single nucleotide polymorphism in tra-3. PLoS Genet 2007, 3(3):e34.

5. Large EE, Xu W, Zhao Y, Brady SC, Long L, Butcher RA, Andersen EC, McGrath PT: Selection on a Subunit of the NURF Chromatin Remodeler Modifies Life History Traits in a Domesticated Strain of Caenorhabditis elegans. PLoS genetics 2016, 12(7):e1006219.

6. Bendesky A, Pitts J, Rockman MV, Chen WC, Tan MW, Kruglyak L, Bargmann Cl: Long-range regulatory polymorphisms affecting a GABA receptor constitute a quantitative trait locus (QTL) for social behavior in Caenorhabditis elegans. PLoS Genet 2012, 8(12):e1003157.

7. Bendesky A, Tsunozaki M, Rockman MV, Kruglyak L, Bargmann Cl: Catecholamine receptor polymorphisms affect decision-making in C. elegans. Nature 2011, 472(7343):313-318.

8. O'Donnell MP, Chao PH, Kammenga JE, Sengupta P: Rictor/TORC2 mediates gut-to-brain signaling in the regulation of phenotypic plasticity in C. elegans. PLoS Genet 2018, 14(2):e1007213.

9. Cook DE, Zdraljevic S, Tanny RE, Seo B, Riccardi DD, Noble LM, Rockman MV, Alkema MJ, Braendle C, Kammenga JE et al: The Genetic Basis of Natural Variation in Caenorhabditis elegans Telomere Length. Genetics 2016, 204(1):371-383.

10. Schmid T, Snoek LB, Frohli E, van der Bent ML, Kammenga J, Hajnal A: Systemic Regulation of RAS/MAPK Signaling by the Serotonin Metabolite 5-HIAA. PLoS Genet 2015, 11(5):e1005236.

11. Seidel HS, Ailion M, Li J, van Oudenaarden A, Rockman MV, Kruglyak L: A novel sperm-delivered toxin causes late-stage embryo lethality and transmission ratio distortion in C. elegans. PLoS Biol 2011, 9(7):e1001115.

12. McGrath PT, Rockman MV, Zimmer M, Jang H, Macosko EZ, Kruglyak L, Bargmann Cl: Quantitative mapping of a digenic behavioral trait implicates globin variation in C. elegans sensory behaviors. Neuron 2009, 61(5):692-699.

13. Reddy KC, Andersen EC, Kruglyak L, Kim DH: A polymorphism in npr-1 is a behavioral determinant of pathogen susceptibility in C. elegans. Science 2009, 323(5912):382-384.

14. Rogers $C$, Persson $A$, Cheung $B$, de Bono $M$ : Behavioral motifs and neural pathways coordinating 02 responses and aggregation in C. elegans. Current biology : $C B$ 2006, 16(7):649659.

15. Gloria-Soria A, Azevedo RB: npr-1 Regulates foraging and dispersal strategies in Caenorhabditis elegans. Current biology : CB 2008, 18(21):1694-1699.

16. Seidel HS, Rockman MV, Kruglyak L: Widespread genetic incompatibility in C. elegans maintained by balancing selection. Science 2008, 319(5863):589-594.

17. Tijsterman M, Okihara KL, Thijssen K, Plasterk RH: PPW-1, a PAZ/PIWI protein required for efficient germline RNAi, is defective in a natural isolate of C. elegans. Current biology : CB 2002, 12(17):1535-1540. 
18. Palopoli MF, Rockman MV, TinMaung A, Ramsay C, Curwen S, Aduna A, Laurita J, Kruglyak L: Molecular basis of the copulatory plug polymorphism in Caenorhabditis elegans. Nature 2008, 454(7207):1019-1022.

19. Reiner DJ, Ailion M, Thomas JH, Meyer BJ: C. elegans anaplastic lymphoma kinase ortholog SCD2 controls dauer formation by modulating TGF-beta signaling. Current biology : CB 2008, 18(15):1101-1109.

20. Zdraljevic S, Fox BW, Strand C, Panda O, Tenjo FJ, Brady SC, Crombie TA, Doench JG, Schroeder FC, Andersen EC: Natural variation in C. elegans arsenic toxicity is explained by differences in branched chain amino acid metabolism. Elife 2019, 8.

21. Hahnel SR, Zdraljevic S, Rodriguez BC, Zhao Y, McGrath PT, Andersen EC: Extreme allelic heterogeneity at a Caenorhabditis elegans beta-tubulin locus explains natural resistance to benzimidazoles. PLoS pathogens 2018, 14(10):e1007226.

22. Zdraljevic S, Strand C, Seidel HS, Cook DE, Doench JG, Andersen EC: Natural variation in a single amino acid substitution underlies physiological responses to topoisomerase II poisons. PLOS genetics 2017, 13(7):e1006891.

23. Ben-David E, Burga A, Kruglyak L: A maternal-effect selfish genetic element in Caenorhabditis elegans. Science 2017, 356(6342):1051-1055.

24. Greene JS, Brown M, Dobosiewicz M, Ishida IG, Macosko EZ, Zhang X, Butcher RA, Cline DJ, McGrath PT, Bargmann Cl: Balancing selection shapes density-dependent foraging behaviour. Nature 2016, 539(7628):254-258.

25. Brady SC, Zdraljevic S, Bisaga KW, Tanny RE, Cook DE, Lee D, Wang Y, Andersen EC: A Novel Gene Underlies Bleomycin-Response Variation in Caenorhabditis elegans. Genetics 2019.

26. Li Y, Breitling R, Snoek LB, van der Velde KJ, Swertz MA, Riksen J, Jansen RC, Kammenga JE: Global genetic robustness of the alternative splicing machinery in Caenorhabditis elegans. Genetics 2010, 186(1):405-410.

27. Singh KD, Roschitzki B, Snoek LB, Grossmann J, Zheng X, Elvin M, Kamkina P, Schrimpf SP, Poulin GB, Kammenga JE et al: Natural Genetic Variation Influences Protein Abundances in C. elegans Developmental Signalling Pathways. PLoS One 2016, 11(3):e0149418.

28. Snoek BL, Sterken MG, Bevers RPJ, Volkers RJM, Van't Hof A, Brenchley R, Riksen JAG, Cossins A, Kammenga JE: Contribution of trans regulatory eQTL to cryptic genetic variation in C. elegans. BMC Genomics 2017, 18(1):500.

29. Sterken MG, Bevers RPJ, Volkers RJM, Riksen JAG, Kammenga JE, Snoek BL: Dissecting the eQTL micro-architecture in Caenorhabditis elegans. BioRxiv 2019.

30. Sterken MG, van Bemmelen van der Plaat L, Riksen JAG, Rodriguez M, Schmid T, Hajnal A, Kammenga JE, Snoek BL: Ras/MAPK Modifier Loci Revealed by eQTL in Caenorhabditis elegans. G3 (Bethesda) 2017, 7(9):3185-3193.

31. Vinuela A, Snoek LB, Riksen JA, Kammenga JE: Genome-wide gene expression regulation as a function of genotype and age in C. elegans. Genome Res 2010, 20(7):929-937.

32. Gao AW, Sterken MG, Uit de Bos J, van Creij J, Kamble R, Snoek BL, Kammenga JE, Houtkooper $\mathrm{RH}$ : Natural genetic variation in C. elegans identified genomic loci controlling metabolite levels. Genome Res 2018, 28(9):1296-1308.

33. Jimenez-Gomez JM, Wallace AD, Maloof JN: Network analysis identifies ELF3 as a QTL for the shade avoidance response in Arabidopsis. PLoS Genet 2010, 6(9):e1001100.

34. Hartanto M, Joosen RVL, Snoek BL, Willems LAJ, Sterken MG, de Ridder D, Hilhorst HWM, Ligterink W, Nijveen H: Network analysis prioritizes DEWAX and ICE1 as the candidate genes for two major eQTL hotspots in seed germination. BioRxiv 2020.

35. Keurentjes JJ, Fu J, Terpstra IR, Garcia JM, van den Ackerveken G, Snoek LB, Peeters AJ, Vreugdenhil D, Koornneef M, Jansen RC: Regulatory network construction in Arabidopsis by 
using genome-wide gene expression quantitative trait loci. Proc Natl Acad Sci U S A 2007, 104(5):1708-1713.

36. Snoek LB, Terpstra IR, Dekter R, Van den Ackerveken G, Peeters AJ: Genetical Genomics Reveals Large Scale Genotype-By-Environment Interactions in Arabidopsis thaliana. Front Genet 2012, 3:317.

37. Li Y, Alvarez OA, Gutteling EW, Tijsterman M, Fu J, Riksen JA, Hazendonk E, Prins P, Plasterk RH, Jansen RC et al: Mapping determinants of gene expression plasticity by genetical genomics in C. elegans. PLoS genetics 2006, 2(12):e222.

38. Cubillos FA, Stegle O, Grondin C, Canut M, Tisne S, Gy I, Loudet O: Extensive cis-regulatory variation robust to environmental perturbation in Arabidopsis. Plant Cell 2014, 26(11):42984310.

39. Rockman MV, Skrovanek SS, Kruglyak L: Selection at linked sites shapes heritable phenotypic variation in C. elegans. Science 2010, 330(6002):372-376.

40. West MA, Kim K, Kliebenstein DJ, van Leeuwen H, Michelmore RW, Doerge RW, St Clair DA: Global eQTL mapping reveals the complex genetic architecture of transcript-level variation in Arabidopsis. Genetics 2007, 175(3):1441-1450.

41. Ranjan A, Budke JM, Rowland SD, Chitwood DH, Kumar R, Carriedo L, Ichihashi Y, Zumstein K, Maloof JN, Sinha NR: eQTL Regulating Transcript Levels Associated with Diverse Biological Processes in Tomato. Plant Physiol 2016, 172(1):328-340.

42. King EG, Merkes CM, McNeil CL, Hoofer SR, Sen S, Broman KW, Long AD, Macdonald SJ: Genetic dissection of a model complex trait using the Drosophila Synthetic Population Resource. Genome research 2012, 22(8):1558-1566.

43. Kover PX, Valdar W, Trakalo J, Scarcelli N, Ehrenreich IM, Purugganan MD, Durrant C, Mott R: A Multiparent Advanced Generation Inter-Cross to fine-map quantitative traits in Arabidopsis thaliana. PLoS genetics 2009, 5(7):e1000551.

44. de Koning DJ, Mclntyre LM: Back to the Future: Multiparent Populations Provide the Key to Unlocking the Genetic Basis of Complex Traits. Genetics 2017, 206(2):527-529.

45. Snoek BL, Volkers RJM, Nijveen H, Petersen C, Dirksen P, Sterken MG, Nakad R, Riksen JAG, Rosenstiel $\mathrm{P}$, Stastna JJ et al: A multi-parent recombinant inbred line population of $\mathrm{C}$. elegans allows identification of novel QTLs for complex life history traits. BMC Biol 2019, 17(1):24.

46. Noble LM, Chelo I, Guzella T, Afonso B, Riccardi DD, Ammerman P, Dayarian A, Carvalho S, Crist A, Pino-Querido A et al: Polygenicity and Epistasis Underlie Fitness-Proximal Traits in the Caenorhabditis elegans Multiparental Experimental Evolution (CeMEE) Panel. Genetics 2017, 207(4):1663-1685.

47. Rockman MV, Kruglyak L: Recombinational landscape and population genomics of Caenorhabditis elegans. PLoS Genet 2009, 5(3):e1000419.

48. Sterken MG, Snoek LB, Kammenga JE, Andersen EC: The laboratory domestication of Caenorhabditis elegans. Trends Genet 2015, 31(5):224-231.

49. Thompson OA, Snoek LB, Nijveen H, Sterken MG, Volkers RJ, Brenchley R, Van't Hof A, Bevers RP, Cossins AR, Yanai I et al: Remarkably Divergent Regions Punctuate the Genome Assembly of the Caenorhabditis elegans Hawaiian Strain CB4856. Genetics 2015, 200(3):975-989.

50. Doroszuk A, Snoek LB, Fradin E, Riksen J, Kammenga J: A genome-wide library of CB4856/N2 introgression lines of Caenorhabditis elegans. Nucleic Acids Res 2009, 37(16):e110.

51. Vinuela A, Snoek LB, Riksen JA, Kammenga JE: Aging Uncouples Heritability and Expression-QTL in Caenorhabditis elegans. G3 (Bethesda) 2012, 2(5):597-605.

52. Jovic K, Sterken MG, Grilli J, Bevers RPJ, Rodriguez M, Riksen JAG, Allesina S, Kammenga JE, Snoek LB: Temporal dynamics of gene expression in heat-stressed Caenorhabditis elegans. PLoS One 2017, 12(12):e0189445. 
53. Kamkina P, Snoek LB, Grossmann J, Volkers RJ, Sterken MG, Daube M, Roschitzki B, Fortes C, Schlapbach R, Roth A et al: Natural Genetic Variation Differentially Affects the Proteome and Transcriptome in Caenorhabditis elegans. Mol Cell Proteomics 2016, 15(5):1670-1680.

54. Nakad R, Snoek LB, Yang W, Ellendt S, Schneider F, Mohr TG, Rosingh L, Masche AC, Rosenstiel $P C$, Dierking $K$ et al: Contrasting invertebrate immune defense behaviors caused by a single gene, the Caenorhabditis elegans neuropeptide receptor gene npr-1. BMC Genomics 2016, 17:280.

55. Rodriguez M, Snoek LB, Riksen JA, Bevers RP, Kammenga JE: Genetic variation for stressresponse hormesis in C. elegans lifespan. Exp Gerontol 2012, 47(8):581-587.

56. Snoek BL, Sterken MG, Hartanto M, van Zuilichem AJ, Kammenga JE, de Ridder D, Nijveen H: WormQTL2: an interactive platform for systems genetics in Caenorhabditis elegans. Database (Oxford) 2020, 2020.

57. Snoek LB, Joeri van der Velde K, Li Y, Jansen RC, Swertz MA, Kammenga JE: Worm variation made accessible: Take your shopping cart to store, link, and investigate! Worm 2014, 3(1):e28357.

58. Snoek LB, Orbidans HE, Stastna JJ, Aartse A, Rodriguez M, Riksen JA, Kammenga JE, Harvey SC: Widespread genomic incompatibilities in Caenorhabditis elegans. G3 (Bethesda) 2014, 4(10):1813-1823.

59. Snoek LB, Van der Velde KJ, Arends D, Li Y, Beyer A, Elvin M, Fisher J, Hajnal A, Hengartner MO, Poulin GB et al: WormQTL--public archive and analysis web portal for natural variation data in Caenorhabditis spp. Nucleic Acids Res 2013, 41(Database issue):D738-743.

60. Stastna JJ, Snoek LB, Kammenga JE, Harvey SC: Genotype-dependent lifespan effects in peptone deprived Caenorhabditis elegans. Sci Rep 2015, 5:16259.

61. Jovic K, Grilli J, Sterken MG, Snoek BL, Riksen JAG, Allesina S, Kammenga JE: Transcriptome resilience predicts thermotolerance in Caenorhabditis elegans. BMC Biol 2019, 17(1):102.

62. Volkers RJ, Snoek LB, Hubar CJ, Coopman R, Chen W, Yang W, Sterken MG, Schulenburg H, Braeckman BP, Kammenga JE: Gene-environment and protein-degradation signatures characterize genomic and phenotypic diversity in wild Caenorhabditis elegans populations. BMC Biol 2013, 11:93.

63. Nijveen H, Ligterink W, Keurentjes JJ, Loudet O, Long J, Sterken MG, Prins P, Hilhorst HW, de Ridder D, Kammenga JE et al: AraQTL - workbench and archive for systems genetics in Arabidopsis thaliana. Plant $J$ 2017, 89(6):1225-1235.

64. Zych K, Snoek BL, Elvin M, Rodriguez M, Van der Velde KJ, Arends D, Westra HJ, Swertz MA, Poulin G, Kammenga JE et al: reGenotyper: Detecting mislabeled samples in genetic data. PLoS One 2017, 12(2):e0171324.

65. Albert FW, Bloom JS, Siegel J, Day L, Kruglyak L: Genetics of trans-regulatory variation in gene expression. Elife 2018, 7.

66. Li H, Handsaker B, Wysoker A, Fennell T, Ruan J, Homer N, Marth G, Abecasis G, Durbin R, Genome Project Data Processing S: The Sequence Alignment/Map format and SAMtools. Bioinformatics 2009, 25(16):2078-2079.

67. Trapnell C, Pachter L, Salzberg SL: TopHat: discovering splice junctions with RNA-Seq. Bioinformatics 2009, 25(9):1105-1111.

68. Trapnell C, Roberts A, Goff L, Pertea G, Kim D, Kelley DR, Pimentel H, Salzberg SL, Rinn JL, Pachter $L$ : Differential gene and transcript expression analysis of RNA-seq experiments with TopHat and Cufflinks. Nature protocols 2012, 7(3):562-578.

69. Kruijer W, Boer MP, Malosetti M, Flood PJ, Engel B, Kooke R, Keurentjes JJ, van Eeuwijk FA: Marker-based estimation of heritability in immortal populations. Genetics 2015, 199(2):379398. 
521 70. Kang HM, Zaitlen NA, Wade CM, Kirby A, Heckerman D, Daly MJ, Eskin E: Efficient control of Variance Parameter Estimation in Linear Mixed Models. Biometrics 1995, 51(4):1440-1450.

72. Speed D, Hemani G, Johnson MR, Balding DJ: Improved heritability estimation from genomewide SNPs. American journal of human genetics 2012, 91(6):1011-1021.

73. R-Core-Team: R: A Language and Environment for Statistical Computing. R Foundation for 